\title{
Structural and perfusion magnetic resonance imaging of congenital lung malformations
}

\author{
Christian J. Kellenberger ${ }^{1,2} \cdot$ Christina Amaxopoulou ${ }^{1,2}$ - Ueli Moehrlen ${ }^{2,3} \cdot$ Peter K. Bode $^{4}$ - Andreas Jung ${ }^{2,5}$. \\ Julia Geiger ${ }^{1,2}$
}

Received: 2 September 2019 / Revised: 30 December 2019 / Accepted: 10 March 2020 /Published online: 17 April 2020

(C) The Author(s) 2020

\begin{abstract}
Background A radiation-free advanced imaging modality is desirable for investigating congenital thoracic malformations in young children.

Objective To describe magnetic resonance imaging (MRI) findings of congenital bronchopulmonary foregut malformations and investigate the ability of lung MRI for their classification.

Materials and methods This is a retrospective analysis of consecutive MRI examinations performed for suspected congenital lung anomalies in 39 children (median age: 3.8 months, range: 2 days-15 years). Morphological and perfusion findings were characterised on respiratory-gated fast spin echo and dynamic contrast-enhanced sequences obtained at 1.5 tesla. Abnormalities were classified independently by two readers and compared to an expert diagnosis based on pathology, surgery and/or other imaging.

Results Main diagnoses included bronchopulmonary lesions in 33 patients, scimitar syndrome in 4 patients, pulmonary arteriovenous malformation and oesophageal duplication cyst in one patient each. Of 46 observed abnormalities, 44 (96\%) were classified correctly with very good interobserver agreement ( $96 \%$ concordance rate). The 39 detected lung lesions included isolated overinflation $(17 / 39,44 \%)$, cystic pulmonary airway malformation $(8 / 39,21 \%)$, bronchopulmonary sequestration $(7 / 39$, $18 \%)$, bronchogenic cyst $(4 / 39,10 \%)$ and hybrid lesion $(3 / 39,8 \%)$. All lung lesions presented as perfusion defect at peak pulmonary enhancement. Non-cystic lesions showed a delayed peak (median delay: $2.8 \mathrm{~s}$, interquartile range: 0.5 to $4.0 \mathrm{~s}$ ) in relation to normal lung parenchyma.

Conclusion A dedicated lung MRI protocol including respiratory compensated sequences, dynamic angiography and perfusion is able to reliably delineate parenchymal and vascular components of congenital bronchopulmonary foregut malformations. Therefore, MRI may be considered for comprehensive postnatal evaluation of congenital thoracic malformations.
\end{abstract}

Keywords Bronchopulmonary malformation $\cdot$ Children $\cdot$ Lung $\cdot$ Magnetic resonance imaging $\cdot$ Perfusion imaging

Christian J. Kellenberger

christian.kellenberger@kispi.uzh.ch

1 Department of Diagnostic Imaging, University Children's Hospital Zürich, Steinwiesstr. 75, CH 8032 Zürich, Switzerland

2 Children's Research Centre, University Children's Hospital Zürich, Zürich, Switzerland

3 Department of Pediatric Surgery, University Children's Hospital Zürich, Zürich, Switzerland

4 Institute of Pathology, University Hospital Zürich, University of Zürich, Zürich, Switzerland

5 Division of Pulmonology, University Children's Hospital Zürich, Zürich, Switzerland

\section{Introduction}

Congenital lung disease includes a broad variety of rare developmental anomalies that may be clinically relevant $[1,2]$, including congenital pulmonary airway malformation (CPAM), bronchopulmonary sequestration, bronchogenic cyst, congenital segmental or lobar overinflation, venolobar syndrome and other vascular malformations. With the advent of prenatal ultrasound (US), congenital lung lesions have been estimated at about 1 in 3,000 live births [3]. Imaging plays an eminent role in lesion detection and characterisation, which are the basis for antenatal and postnatal management of affected foetuses and infants. Many congenital thoracic malformations are considered a spectrum of an in utero airway obstruction-lung malformation sequence with accompanying 
vascular anomalies $[1,2]$. Systematic evaluation of all components (airway, lung parenchyma and vasculature) is mandatory for lesion delineation and classification [4]. Accurate diagnosis and localisation of the different entities may influence patient management or provide important information for surgery.

During pregnancy, US and magnetic resonance imaging (MRI) are commonly used to monitor lung lesions [5-10], while postnatal assessment usually relies on chest radiography and computed tomography (CT) $[2,11,12]$. As prenatal evaluation and chest radiography are not very reliable for fully defining the type of lesion [1, 2, 13], and because lesions that apparently disappear during pregnancy may still be detectable after birth $[2,13]$, it is general practice to investigate affected children by contrast-enhanced CT postnatally before 6 weeks of age or between 3 and 12 months $[6,14,15]$. Multi-detector chest $\mathrm{CT}$ angiography has been suggested for assessing potential extrapulmonary blood supply $[11,14]$.

The main disadvantage of $\mathrm{CT}$ in the paediatric population is ionising radiation, which can still be considered significant even when ALARA (as low as reasonably achievable) principles and iterative reconstruction techniques are applied, resulting in estimated effective doses of about $1-2 \mathrm{mSv}$ for an infant $[12,16]$. Serial CT, which has been recommended by some centres for following asymptomatic lesions for up to 10 years $[6,17,18]$, adds to the radiation burden. Therefore, a radiation-free technique is desirable for diagnosing and monitoring congenital lung lesions. Although MRI has been advocated for assessing solid and vascular components of congenital lung lesions, it is generally not considered a first-line modality for characterising lung parenchymal abnormalities [11, 14, 19, 20].

Since the introduction of a dedicated lung MRI protocol at our institution in 2013, we have increasingly imaged children with congenital lung abnormalities. The aim of this work is to describe the MRI findings of congenital bronchopulmonary foregut malformations and investigate the diagnostic performance of MRI for their classification.

\section{Materials and methods}

\section{Patients}

In this retrospective study, lung MRI studies performed to assess congenital lung lesions from July 2013 to July 2019 were searched on the picture archiving and communication system (PACS) of our tertiary university paediatric hospital. All available imaging studies and electronic medical records were reviewed for the 39 consecutive patients identified. During the same 6-year period, 335 lung MRI examinations were performed at our institution.

Detection and classification of the lung lesions on MRI were compared to a final diagnosis reached by an expert consensus panel (C.J.K., a radiologist with 21 years of experience in paediatric chest imaging and MRI; P.K.B., a paediatric pathologist with 16 years of experience; and U.M., a surgeon with 15 years of experience in paediatric general and thoracic surgery) based on surgery, pathology, other imaging (including prenatal and follow-up studies) and/or clinical follow-up. The MRI morphology and perfusion of the congenital abnormalities were described. The included patients and/or their parents had given consent to retrospective data analysis. The study was approved by the responsible governmental ethics committee. As part of the clinical hospital routine, patients and/or parents consented to MRI with contrast administration and sedation when applicable.

\section{Lung magnetic resonance imaging}

All MRI scans were performed on a 1.5-T scanner (Discovery MR 450; GE Healthcare, Waukesha, WI) with a multi-array flexible surface coil covering the chest. Most of the children $(37 / 39,94.9 \%)$ were imaged under sedation with propofol $(n=27)$, chloral hydrate $(n=2)$ or general anaesthesia with intubation $(n=8)$ applied by anaesthesiologists according to hospital routine.

As described previously [21], the routine protocol included fast imaging employing steady-state acquisition (FIESTA) in three orthogonal planes, axial and coronal partial Fourier acquisition single-shot fast spin echo (SSFSE), axial respiratory-gated T2-weighted fast spin echo sequence with periodically rotated overlapping parallel lines with enhanced reconstruction (PROPELLER), coronal respiratory-gated proton-density weighted fast spin echo sequence (FSE), as well as axial and coronal T1-weighted fast spin echo or fast spoiled gradient echo acquisition in the steady state (FSPGR) before and after intravenous contrast injection. Perfusion imaging was performed with a dynamic contrast-enhanced three-dimensional gradient echo sequence (time-resolved imaging of contrast kinetics [TRICKS angiography]). By under-sampling the peripheral $\mathrm{k}$-space and parallel imaging, we achieved a temporal resolution of 1-2 s. Image acquisition was started with intravenous injection of a short bolus of gadoliniumbased contrast agent $(0.1 \mathrm{mmol} / \mathrm{kg}$ body weight; gadoteric acid; [Dotarem; Guerbet AG, Zürich, Switzerland]) and comprised 40 phases (duration: $40-80$ s). Typical sequence parameters for imaging the lung in an infant are given in Table 1 . The time for the MRI study, including time for sedation, ranged from 30 to $40 \mathrm{~min}$; the mean imaging time for acquiring all MRI sequences was about $20 \mathrm{~min}$.

\section{Image evaluation and lesion classification}

All lung MRI examinations were reviewed separately on a PACS workstation (IDS7; Sectra Medical Systems, Linköping, Sweden) by two paediatric radiologists (J.G., 
Table 1 Lung magnetic resonance imaging protocol for infants

\begin{tabular}{|c|c|c|c|c|c|c|}
\hline $\begin{array}{l}\text { Sequence } \\
\text { Imaging planes }\end{array}$ & $\begin{array}{l}\text { FIESTA } \\
\text { Axial, coronal, sagittal }\end{array}$ & $\begin{array}{l}\text { SSFSE } \\
\text { Axial, coronal, sagittal }\end{array}$ & $\begin{array}{l}\text { T2-PROPELLER } \\
\text { Axial }\end{array}$ & $\begin{array}{l}\text { PD-FSE } \\
\text { Coronal }\end{array}$ & $\begin{array}{l}\text { TRICKS } \\
\text { Coronal }\end{array}$ & $\begin{array}{l}\text { T1-PROPELLER } \\
\text { Axial }\end{array}$ \\
\hline Repetition time (ms) & 3.5 & 280 & 2,500 & 2,500 & 3.1 & 570 \\
\hline Echo time (ms) & 1.5 & 34 & 46 & 11 & 1.3 & 10 \\
\hline Flip angle $\left(^{\circ}\right)$ & 45 & 90 & 140 & 90 & 25 & 90 \\
\hline Echo train length & na & ss & 16 & 30 & na & 6 \\
\hline Number of excitations & 1 & $\mathrm{hF}$ & 2.6 & 4 & $\mathrm{hF}$ & 3 \\
\hline Fat saturation & no & no & yes & no & no & yes \\
\hline Respiratory gating & no & no & yes & yes & no & no \\
\hline Slice $(\mathrm{mm})$ & 4 & 4 & 4 & 4 & 2.5 & 4 \\
\hline Field of view (cm) & 27 & 27 & 22 & 22 & 22 & 22 \\
\hline Matrix & $160 \times 256$ & $288 \times 192$ & $288 \times 288$ & $352 \times 256$ & $256 \times 160$ & $320 \times 320$ \\
\hline Imaging time & $3 \times 20 \mathrm{~s}$ & $3 \times 10 \mathrm{~s}$ & $4 \mathrm{~min}$ & $3 \min$ & $40 \mathrm{~s}$ & $2 \times 5 \min$ \\
\hline
\end{tabular}

FIESTA fast imaging employing steady-state acquisition, $h F$ half-Fourier acquisition, $n a$ not applicable, $P D-F S E$ proton density weighted fast spin echo, sS single shot, SSFSE half-acquisition single-shot fast spin echo, T1-PROPELLER T1-weighted periodically rotated overlapping parallel lines with enhanced reconstruction obtained after contrast administration, T2-PROPELLER T2-weighted periodically rotated overlapping parallel lines with enhanced reconstruction, TRICKS time-resolved imaging of contrast kinetics

10 years' experience, and C.J.K.) to assess inter-reader agreement for detection and classification of the lung lesions. Discrepant results were resolved in a consensus reading. To assess intra-reader agreement and agreement of MRI with CT, one reader (C.J.K.) performed a formal reading of the available $\mathrm{CT}$ studies and repeated the MRI assessment after an interval of 5 months.

On MRI, morphological assessment of the lung parenchyma and mediastinum relied mainly on the respiratory gated fast spin echo sequences. Abnormalities of the vasculature and lung perfusion were sought on the contrast-enhanced dynamic series.

The location and characteristics of the detected lesions were described. The lesions were categorised as cystic filled with air or fluid, and consolidated or overinflated (decreased parenchymal intensity without discernible cysts). The size and number of cysts were noted. One observer (C.J.K.) measured the size of the lung lesions on both CT and MRI at two separate readings.

Structures with high signal intensity on T2-weighted images within the lesions were noted and interpreted as mucus-filled bronchial structures. Systemic arterial supply and anomalous venous drainage were sought on angiographic images from the dynamic contrast-enhanced series. Perfusion of the lung lesions was qualitatively assessed on parametric images (subtraction images at signal peak enhancement of the lungs, and enhancement integral representing pulmonary blood volume) that were constructed with commercially available software (Volume Viewer, AW Server 3.2; GE Healthcare). Perfusion of the lesion was rated in comparison to unaffected lung parenchyma as absent, decreased, normal or increased. Timing of peak enhancement of the lesion was compared to that of surrounding lung parenchyma and rated as normal or delayed.
One reader (C.J.K.) measured average signal intensity at peak enhancement and signal enhancement integral for all lung lesions and corresponding normal lung parenchyma with a fixed size region of interest (ROI; area range: 0.5 to $1 \mathrm{~cm}^{2}$ ) per patient. The time interval between peak enhancement of the lung lesion and normal parenchyma was noted. Ratios for signal enhancement integral were calculated between lesions and normal lung parenchyma.

Based on location, morphological and perfusion findings, the observed abnormalities were classified into nine categories, including different foregut cysts, lesions with pulmonary overinflation, cystic pulmonary malformations, and predominantly vascular lesions and scimitar syndrome. The designations, synonyms, pathology and imaging findings of the different entities diagnosed in our cohort are detailed in Table 2 and illustrated with Figs. 1, 2, 3, 4 and 5.

\section{Statistical analysis}

Descriptive data were checked with the Shapiro-Wilk W test for normal distribution. Data with normal distribution are given as mean \pm standard deviation (SD). Data without normal distribution are given as median and interquartile range (IQR). Frequencies are given as fraction and percentage. Agreement between MRI and final expert diagnosis, agreement between MRI and CT in a subgroup of patients with both modalities available, intra-reader agreement and interreader agreement for classifying the congenital abnormalities on MRI were described with concordance rates. Perfusion measures were compared between lesions and normal lung parenchyma with a paired samples $t$-test and between different lesions with an independent samples $t$-test. The statistical 
Table 2 Classification of congenital bronchopulmonary, lung and vascular malformations in 39 patients with magnetic resonance imaging

\begin{tabular}{|c|c|c|}
\hline Entity (synonyms) & Pathology & Imaging findings (MRI and CT) \\
\hline Bronchogenic cyst & $\begin{array}{l}\text { Fluid-filled cyst lined by respiratory } \\
\text { type epithelium with underlying } \\
\text { fascicles of smooth muscle and } \\
\text { mature cartilage }\end{array}$ & $\begin{array}{l}\text { Solitary unilocular cyst filled with fluid/mucus } \\
\text { adjacent to central airways or in the periphery } \\
\text { of the lung }\end{array}$ \\
\hline Oesophageal duplication cyst & $\begin{array}{l}\text { Fluid-filled cyst attached to oesophagus } \\
\text { and covered by } 2 \text { muscle layers }\end{array}$ & $\begin{array}{l}\text { Solitary fluid-filled cyst bordering the } \\
\text { oesophagus }\end{array}$ \\
\hline $\begin{array}{l}\text { Isolated overinflation (isolated } \\
\text { bronchial atresia, segmental } \\
\text { or lobar emphysema/ } \\
\text { hyperinflation/overinflation) }\end{array}$ & $\begin{array}{l}\text { Obstruction to airways } \\
\text { at different levels } \\
\text { Normal lung parenchyma } \\
\text { with airspace enlargement }\end{array}$ & $\begin{array}{l}\text { Lobar, segmental or subsegmental area with } \\
\text { decreased signal intensity or attenuation, } \\
\text { 土mass effect or architectural distortion, } \\
\pm \text { fluid-filled dilated bronchial structures } \\
\text { (mucocele, linear hyperintensities) }\end{array}$ \\
\hline $\begin{array}{l}\text { Overinflation with systemic } \\
\text { feeding artery (bronchopulmonary } \\
\text { sequestration) }\end{array}$ & +systemic artery to lesion & $\begin{array}{l}\text { Findings of overinflation or consolidation, and } \\
\text { systemic artery supplying the lesion }\end{array}$ \\
\hline $\begin{array}{l}\text { Overinflation with systemic feeding } \\
\text { artery and cysts (hybrid lesion: } \\
\text { bronchopulmonary sequestration } \\
\text { with parenchymal cysts) }\end{array}$ & $\begin{array}{l}\text { +systemic artery to lesion } \\
\text { +multiple small cysts (CPAM type } 2 \text { ) }\end{array}$ & $\begin{array}{l}\text { Findings of overinflation or consolidation, } \\
\text { systemic artery supplying the lesion and } \\
\text { identifiable parenchymal air-filled cysts } \\
(<2 \mathrm{~cm})\end{array}$ \\
\hline $\begin{array}{l}\text { Cystic congenital pulmonary airway } \\
\text { malformation (congenital cystic } \\
\text { adenomatoid malformation } \\
\text { [CCAM], congenital pulmonary } \\
\text { airway malformation [CPAM]) }\end{array}$ & $\begin{array}{l}\text { CPAM type } 1 \text { (large cyst lesion) } \\
\text { CPAM type } 2 \text { (small cyst lesion) }\end{array}$ & $\begin{array}{l}\text { Single predominant or multiple air-filled or } \\
\text { air/fluid-filled cysts (largest cyst }>2 \mathrm{~cm}) \\
\text { Multiple small cysts }(<2 \mathrm{~cm}) \pm \text { solid or } \\
\text { hyperinflated lung areas }\end{array}$ \\
\hline $\begin{array}{l}\text { Systemic arterial supply to normal lung } \\
\text { (major aortopulmonary collateral } \\
\text { arteries [MAPCA]) }\end{array}$ & & $\begin{array}{l}\text { Systemic arterial supply to normally } \\
\text { aerated lung parenchyma }\end{array}$ \\
\hline Pulmonary arteriovenous malformation & & $\begin{array}{l}\text { Anomalous connection between peripheral } \\
\text { pulmonary artery and vein }\end{array}$ \\
\hline $\begin{array}{l}\text { Scimitar syndrome (venolobar } \\
\text { syndrome, hypogenetic lung } \\
\text { syndrome) }\end{array}$ & & $\begin{array}{l}\text { Hypoplastic right lung with two lobes } \\
\text { Hypoplastic right pulmonary artery } \\
\text { Partial anomalous venous drainage } \\
\pm \text { systemic arterial supply to lower lobe } \\
\pm \text { diaphragmatic hernia, horseshoe lung }\end{array}$ \\
\hline
\end{tabular}

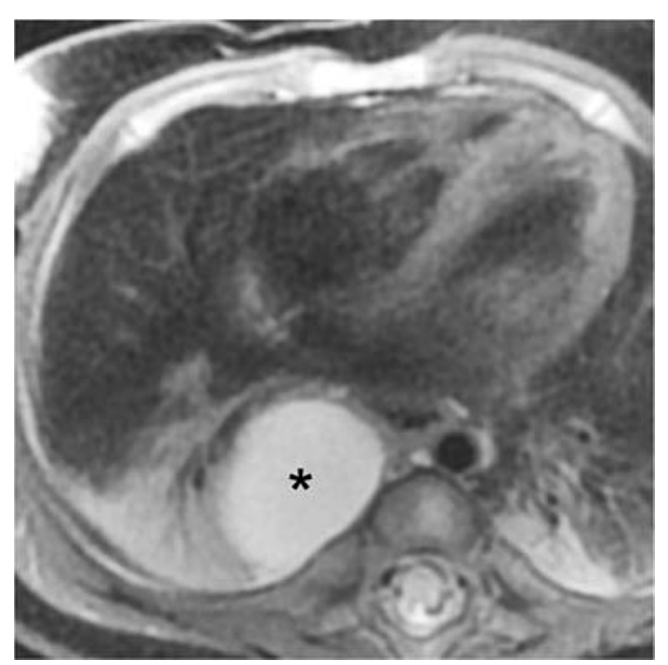

Fig. 1 Oesophageal duplication cyst in a 3-month-old girl with foetal ultrasound diagnosis of cystic congenital pulmonary airway malformation. Axial fat-saturated T2-weighted image shows broad connection of the unilocular fluid-filled cyst $(*)$ with the oesophageal wall analysis was performed with MedCalc Statistical Software version 19.0.5 (MedCalc Software Ltd., Ostend, Belgium). A $P$-value $<0.05$ was considered significant.

\section{Results}

\section{Patients}

The study population consisted of 39 children, 18 girls and 21 boys, with a median age of 3.8 months, interquartile range of 3.1 to 12.1 months and age range of 2 days to 14.7 years at MRI examination.

\section{Diagnostic performance of MRI}

In Table 3, the clinical presentation, MRI findings and final expert diagnosis are detailed for all patients and lesions. The final diagnosis was supported by pathology in $24 / 39(61.5 \%)$ 
Fig. 2 Bronchogenic cysts in an 8 -week-old boy. a Coronal proton density MR image shows a single air-filled cyst $(*)$ in the left upper lobe following thoraco-amniotic drainage in utero. b Axial T2 weighted image shows a second mediastinal fluid-filled cyst (**) with connection to the tracheal wall
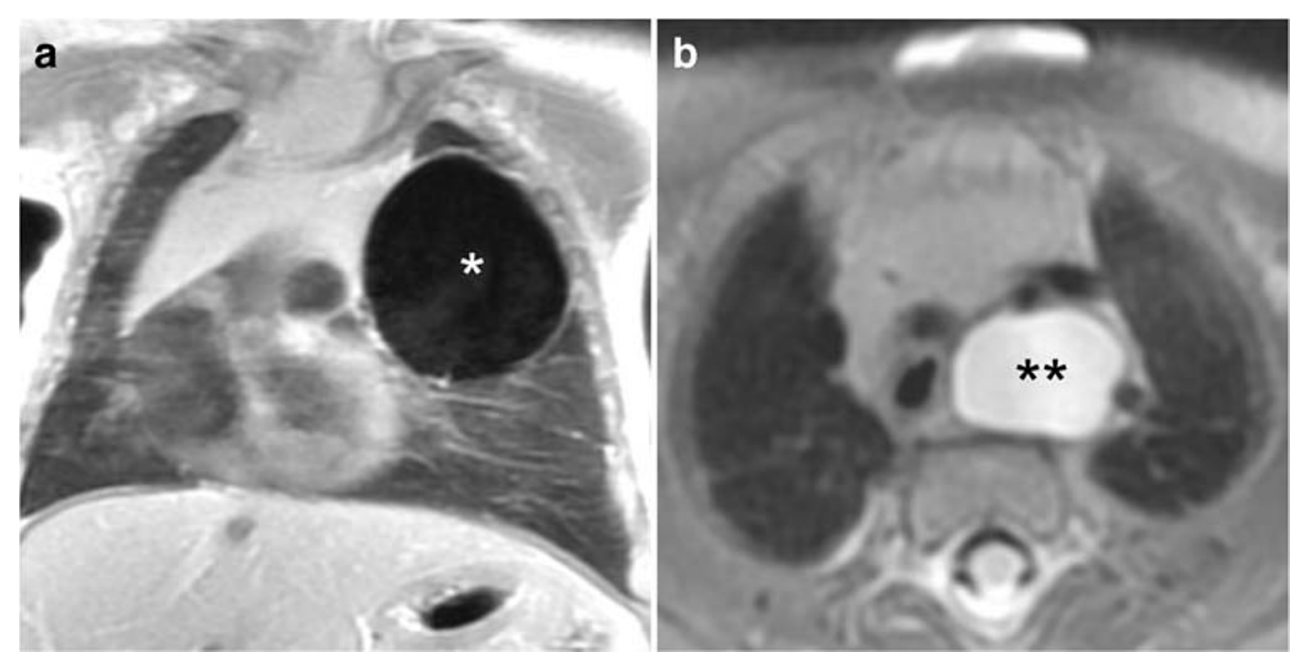
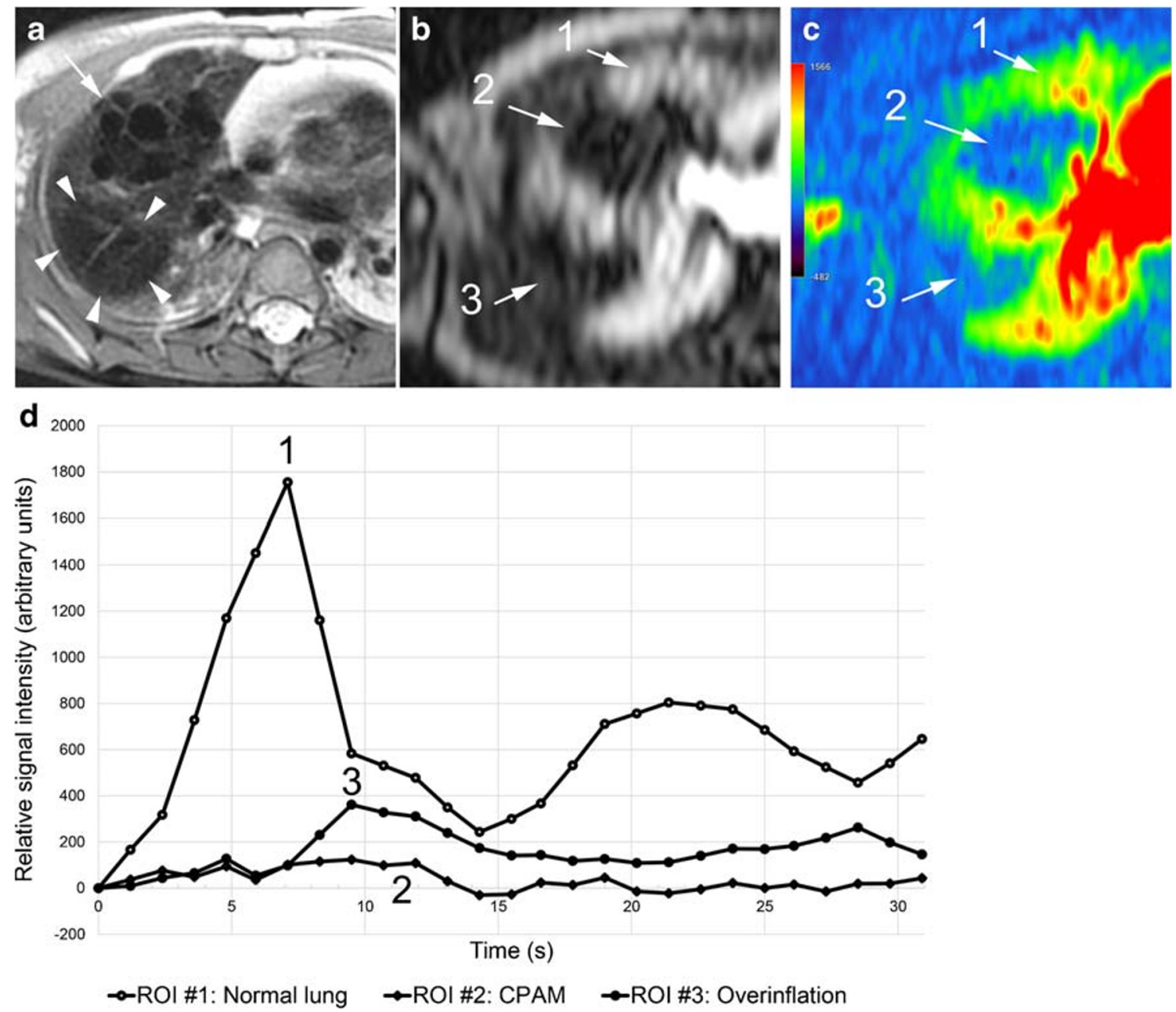

Fig. 3 Cystic congenital pulmonary airway malformation (CPAM) type 2 and isolated overinflation in an 8-month-old girl. a Axial T2-weighted image shows multiple air-filled cysts (arrow) in the anterior upper lobe segment and overinflation of the posterior upper lobe segment (arrowheads). b, c Axial image at peak enhancement (b) and

parametric map (enhancement integral) (c) show the CPAM (2 in b, c) and isolated overinflation ( 3 in $\mathbf{b}, \mathbf{c}$ ) as perfusion defects. d Signal intensity - time curves show minimal perfusion of the CPAM ( 2 in $\mathbf{d}$ ) and delayed enhancement of the overinflation ( 3 in d) in comparison to normal lung parenchyma ( 1 in $\mathbf{b}, \mathbf{c}$ and $\mathbf{d})$. ROI region of interest 

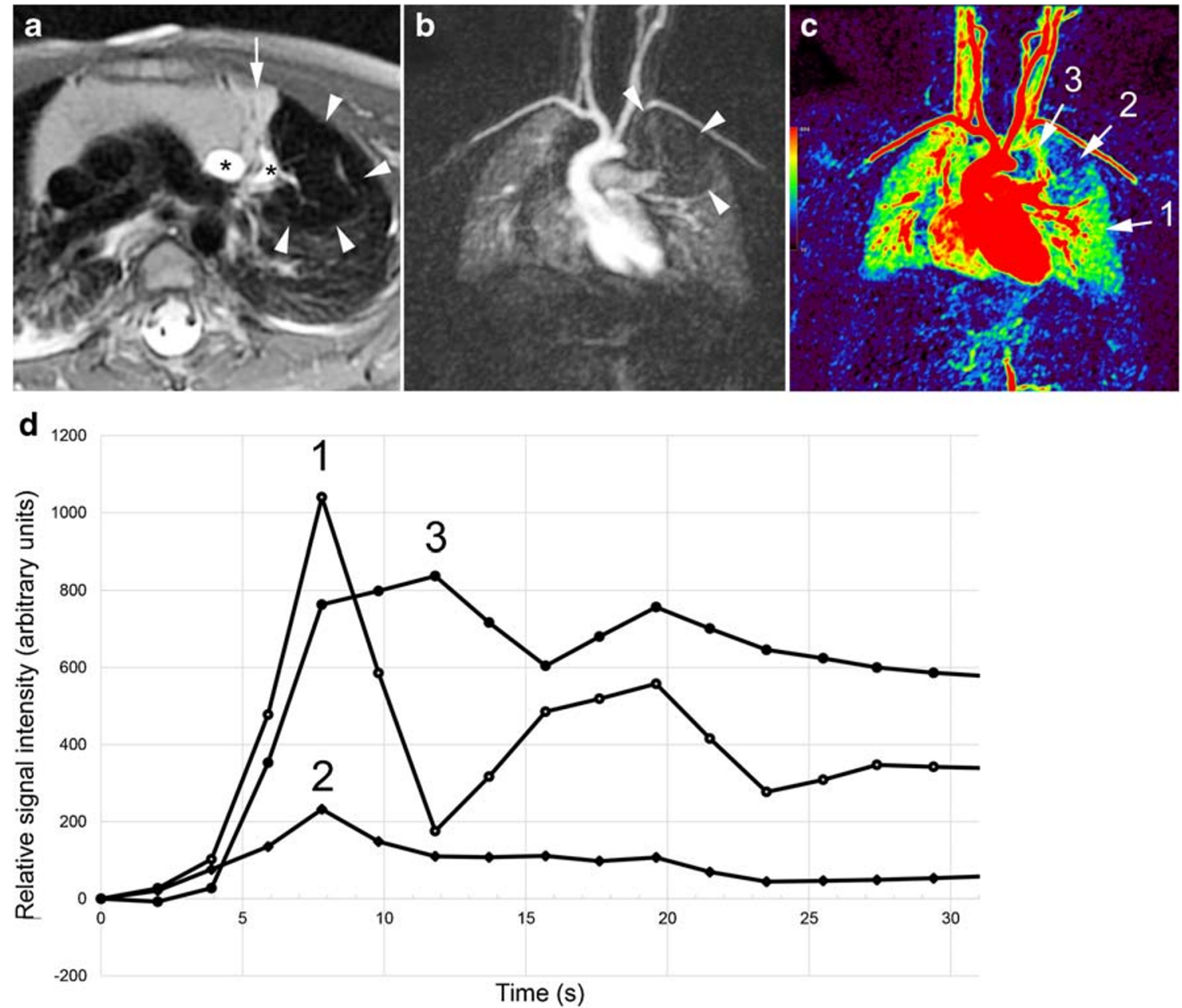

- $\mathrm{ROI}$ \#1: Normal lung $\rightarrow$ ROI \#2: Overinflation $\rightarrow$ ROI \#3: Consolidation

Fig. 4 Isolated overinflation (bronchial atresia) in an 11-month-old boy. a Axial T2-weighted image shows a hypointense lung area (arrowheads) with rarefication of the pulmonary markings, central fluid-filled round and linear bronchial structures (*, mucoceles), and some consolidation (arrow). b Coronal contrast-enhanced image at pulmonary peak enhancement shows the pulmonary lesion as a perfusion defect

patients and 28/46 (60.9\%) abnormalities. In another 3/39 (7.7\%) patients and $3 / 46(6.5 \%)$ abnormalities, the findings were confirmed at surgery. In the remaining 12/39 (30.8\%) patients and 15/46 (32.6\%) abnormalities, the final diagnosis was confirmed by other imaging.

The indication for MRI was prenatal detection of a lung lesion in 25/39 (64.1\%) patients, an incidental imaging finding in $7 / 39$ (17.9\%) patients and respiratory symptoms in $7 / 39$ (17.9\%) patients. The main MRI diagnoses were a congenital bronchopulmonary lesion in 33/39 (84.6\%) patients, scimitar syndrome in $4 / 39(10.3 \%)$ patients, pulmonary arteriovenous malformation in $1 / 39(2.6 \%)$ and oesophageal duplication cyst (Fig. 1) in 1/39 (2.6\%) patients. Overall, $44 / 46(95.7 \%, 95 \%$ confidence interval [CI] $85.2 \%$ to $99.5 \%$ ) abnormalities were correctly diagnosed (Table 3 ). (arrowheads). c Coronal parametric map (enhancement integral). d Signal intensity - time curves. There is decreased perfusion of the overinflated area with pulmonary arterial peak ( 2 in $\mathbf{c}$ and $\mathbf{d}$ ), while the consolidation ( 3 in $\mathbf{c}$ and $\mathbf{d}$ ) shows delayed peak enhancement when compared to normal lung parenchyma ( 1 in $\mathbf{c}$ and $\mathbf{d}$ ). ROI region of interest

In the 33 patients with congenital bronchopulmonary abnormalities, 39 lung lesions were detected, including isolated overinflation $(17 / 39,43.6 \%)$, cystic congenital pulmonary airway malformations $(8 / 39,20.5 \%)$, bronchopulmonary sequestrations $(7 / 39,17.9 \%)$, bronchogenic cysts $(4 / 39,10.3 \%)$ and hybrid lesions $(3 / 39,7.7 \%)$. These bronchopulmonary abnormalities were correctly classified on MRI in $37 / 39$ cases $(94.9 \%$, 95\% CI $82.7 \%$ to $99.4 \%$ ). An isolated bronchial atresia was misdiagnosed as cystic pulmonary airway malformation because dilated segmental bronchi were partially filled with fluid and air resembling air filled cysts (Case 12). An isolated overinflation with small cysts was misdiagnosed as a hybrid lesion because a phrenic artery was mistaken as a systemic artery supplying the lung lesion (Case 16), which was not confirmed at surgery. In the subgroup of 24 patients with resected lung 
Fig. 5 Bronchopulmonary sequestration in a 3-month-old boy. a Coronal proton density MR image shows consolidation in the left lower lobe $(* *)$ and prominent vessels with flow voids. b Left anterior oblique volume rendered angiographic view shows the lung lesion (**), its systemic arterial supply (arrowhead) from the descending aorta and venous drainage (arrow) to the left lower pulmonary vein. $\mathbf{c}, \mathbf{d}$ Coronal image at peak pulmonary enhancement (c) shows a perfusion defect $(* *)$ and parametric map (enhancement integral) (d) shows increased perfusion (**) compared to normal lung (* in $\mathbf{c}$ and $\mathbf{d}$ )
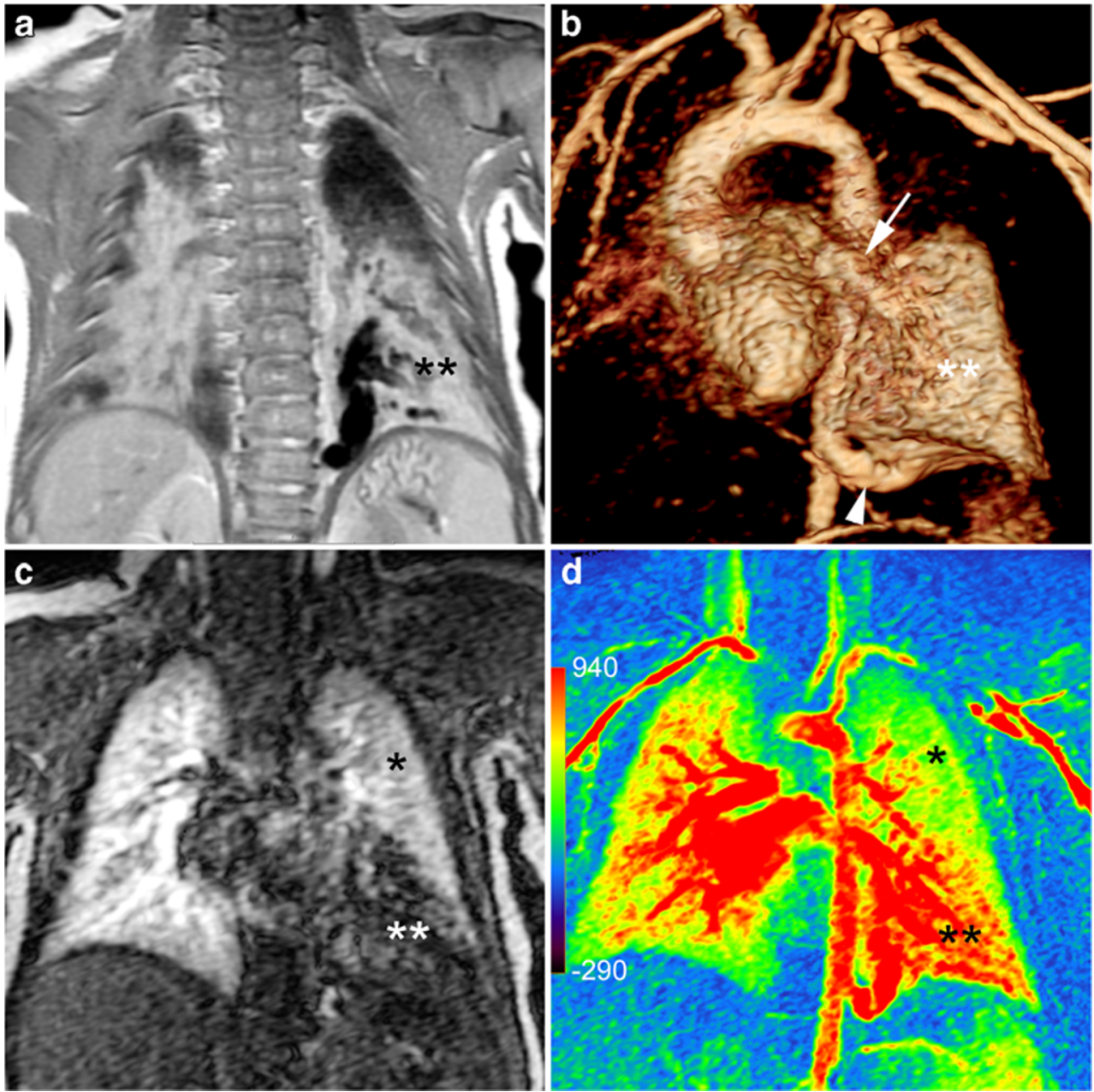

lesions (28 lesions), the concordance rate between MRI and pathology was $26 / 28$ (92.9\%, $95 \%$ CI $76.5 \%$ to $99.1 \%$ ) for lesion diagnosis and detection of systemic arterial supply.

Intra-reader and inter-reader agreement for classifying all 46 detected congenital abnormalities listed in Table 3 was high with concordance rates of $97.8 \%$ (95\% CI $88.5 \%$ to $99.9 \%$ ) and $95.7 \%$ (95\% CI $85.2 \%$ to $99.5 \%$ ), respectively. One observer missed a systemic artery in a lung lesion and in another case misinterpreted the right phrenic artery as systemic arterial supply to the lung lesion. There was complete agreement between the readers for locating the lesions to lung lobes or mediastinum.

\section{Morphology and perfusion of the bronchopulmonary abnormalities (Table 3)}

Bronchogenic cysts were defined as a single unilocular cyst filled with high signal intensity fluid (three cases). In one patient, a large bronchogenic cyst had been treated in utero with a thoraco-amniotic shunt and presented as a single airfilled cyst at 2 months of age (Fig. 2). Air-filled cysts (Fig. 3) of varying size and number were detected in cystic congenital pulmonary airway malformations (eight lesions) or hybrid lesions (three lesions). All cystic lesions (eight congenital pulmonary airway malformations, four bronchogenic cysts, three hybrid lesions and one oesophageal duplication cyst) showed no contrast enhancement within the cyst lumen.

Most of the lesions classified as isolated overinflation (14/ 17, 82.4\%) (Figs. 3 and 4) presented as a hypointense lung area with architectural distortion $(10 / 14,24.4 \%)$ and small solid areas $(5 / 14,50 \%)$. Only $3 / 17$ (17.6\%) parenchymal areas of isolated overinflation, which were imaged during the first 3 days after birth, were filled with fluid showing homogenous high signal on T2-weighted images.

Most bronchopulmonary sequestrations $(6 / 7,85.7 \%)$ presented as consolidation (Fig. 5). Highly intense linear or branching structures were seen centrally in isolated overinflation $(7 / 17,41.2 \%)$ (Fig. 4), in bronchopulmonary sequestration $(6 / 7,85.7 \%)$ and in hybrid lesions $(2 / 3,66.7 \%)$.

The four lung areas with systemic perfusion in scimitar syndrome were hardly detectable on morphological sequences but were clearly evident as perfusion defects on images at peak lung enhancement. 
Table 3 MRI findings and diagnoses of 46 abnormalities in 39 patients with congenital bronchopulmonary foregut malformations

\begin{tabular}{|c|c|c|c|c|c|c|c|}
\hline Case \# & Final diagnosis & Presentation & Patient age & MRI findings & Location & Proof of diagnosis & Management \\
\hline 11 & Bronchogenic cyst & Incidental finding & 15 years & $\begin{array}{l}\text { Unilocular fluid-filled } \\
\text { cyst }\end{array}$ & Subcarinal & Pathology & Cyst resection \\
\hline 31 & Bronchogenic cyst & Incidental finding & 3 years & $\begin{array}{l}\text { Unilocular fluid-filled } \\
\text { cyst }\end{array}$ & Paratracheal & CXR & Conservative \\
\hline 32 & $\begin{array}{l}\text { Bronchogenic cyst } \\
\text { (with drainage in utero) }\end{array}$ & Prenatal diagnosis & 4 months & Large air-filled cyst & LUL & Pathology & Lobectomy \\
\hline 32 & Bronchogenic cyst & Incidental finding & 4 months & Fluid-filled cyst & Paratracheal & Pathology & Cyst resection \\
\hline 36 & Oesophageal duplication cyst & Prenatal diagnosis & 3 months & Fluid-filled cyst & Paravertebral & Pathology & Cyst resection \\
\hline 12 & $\begin{array}{l}\text { Bilobar overinflation (atresia } \\
\text { intermediate bronchus) }\end{array}$ & Prenatal diagnosis & 2 days & $\begin{array}{l}\text { Air-filled cysts } \\
\text { surrounded by } \\
\text { fluid-filled lung } \\
\text { parenchyma }\end{array}$ & ML, RLL & Pathology & Bilobectomy \\
\hline 7 & Lobar overinflation & Airway infection & 9 months & Lobar overinflation & LUL & Pathology & Lobectomy \\
\hline 25 & Lobar overinflation & Prenatal diagnosis & 3 months & Lobar overinflation & LUL & $\begin{array}{l}\text { Foetal US, } \\
\quad \text { follow-up MRI }\end{array}$ & Conservative \\
\hline 27 & Lobar overinflation & Respiratory distress & 13 months & Lobar overinflation & LUL & Follow-up CXR & Conservative \\
\hline 1 & $\begin{array}{l}\text { Segmental overinflation } \\
\text { (bronchial atresia) }\end{array}$ & Prenatal diagnosis & 11 months & $\begin{array}{l}\text { Areas of consolidation } \\
\text { and overinflation, } \\
\text { mucocele }\end{array}$ & LUL & Pathology & Lobectomy \\
\hline 9 & Segmental overinflation & Prenatal diagnosis & 8 months & Segmental overinflation & RUL & Pathology, CT & Lobectomy \\
\hline 9 & Segmental overinflation & Prenatal diagnosis & 8 months & Segmental overinflation & ML & Pathology, CT & Lobectomy \\
\hline 20 & Segmental overinflation & Incidental finding & 3 days & $\begin{array}{l}\text { Partly fluid- and air-filled } \\
\text { lung segment }\end{array}$ & RLL & Follow-up MRI, CT & Conservative \\
\hline 20 & Segmental overinflation & Incidental finding & 3 days & $\begin{array}{l}\text { Partly fluid- and air-filled } \\
\text { lung segment }\end{array}$ & LLL & Follow-up MRI, CT & Conservative \\
\hline 24 & Segmental overinflation & Prenatal diagnosis & 4 months & Segmental overinflation & RLL & Foetal US & Conservative \\
\hline 26 & Segmental overinflation & Respiratory distress & 7 months & Segmental overinflation & LUL & Follow-up CXR & Conservative \\
\hline 37 & Segmental overinflation & Prenatal diagnosis & 14 months & Segmental overinflation & LLL & Foetal US and MRI & Conservative \\
\hline 8 & Subsegmental overinflation & Prenatal diagnosis & 2 months & $\begin{array}{l}\text { Architectural distortion, } \\
\text { small consolidation }\end{array}$ & RLL & Pathology & Lobectomy \\
\hline 10 & Subsegmental overinflation & Prenatal diagnosis & 7 months & $\begin{array}{l}\text { Subsegmental } \\
\text { overinflation }\end{array}$ & RUL & Foetal US and MRI & Conservative \\
\hline 29 & Subsegmental overinflation & Incidental finding & 13 months & $\begin{array}{l}\text { Subsegmental } \\
\text { overinflation }\end{array}$ & RUL & CT, follow-up MRI & Conservative \\
\hline 37 & Subsegmental overinflation & Prenatal diagnosis & 14 months & $\begin{array}{l}\text { Subsegmental } \\
\text { overinflation }\end{array}$ & LUL & Foetal US and MRI & Conservative \\
\hline 3 & Intralobar sequestration & Prenatal diagnosis & 4 months & $\begin{array}{l}\text { Segmental overinflation, } \\
\text { systemic artery }\end{array}$ & RLL & Pathology, CT & Lobectomy \\
\hline 6 & Intralobar sequestration & Prenatal diagnosis & 4 months & $\begin{array}{l}\text { Consolidation, } \\
\text { systemic artery }\end{array}$ & RLL & Pathology & Lobectomy \\
\hline 13 & Intralobar sequestration & Prenatal diagnosis & 3 months & $\begin{array}{l}\text { Consolidation, } \\
\text { systemic arteries }\end{array}$ & RLL & Pathology & Lobectomy \\
\hline 30 & Intralobar sequestration & Prenatal diagnosis & 6 days & $\begin{array}{l}\text { Consolidation } \\
\text { containing small } \\
\text { fluid-filled structures, } \\
\text { systemic artery }\end{array}$ & RLL & Pathology & Lobectomy \\
\hline 33 & Intralobar sequestration & Prenatal diagnosis & 3 months & $\begin{array}{l}\text { Consolidation, } \\
\text { systemic artery }\end{array}$ & LLL & Pathology & $\begin{array}{l}\text { Segment } \\
\text { resection }\end{array}$ \\
\hline 38 & Intralobar sequestration & Prenatal diagnosis & 3 months & $\begin{array}{l}\text { Consolidation, } \\
\text { systemic artery }\end{array}$ & LLL & Pathology & Lobectomy \\
\hline 13 & Extralobar sequestration & Prenatal diagnosis & 3 months & $\begin{array}{l}\text { Consolidation, systemic } \\
\text { arteries, contralateral } \\
\text { pulmonary venous } \\
\text { drainage }\end{array}$ & LLL & Pathology & Lobectomy \\
\hline 15 & Hybrid lesion & $\begin{array}{l}\text { Recurrent } \\
\text { pneumonia }\end{array}$ & 4 years & $\begin{array}{l}\text { Small air-filled cysts, } \\
\text { consolidation, } \\
\text { systemic artery }\end{array}$ & LLL & Pathology, CT & Lobectomy \\
\hline 17 & Hybrid lesion & Prenatal diagnosis & 5 months & $\begin{array}{l}\text { Small air-filled cysts, } \\
\text { consolidation, } \\
\text { systemic artery }\end{array}$ & RLL & $\begin{array}{l}\text { Foetal US and MRI, } \\
\text { follow-up MRI }\end{array}$ & Conservative \\
\hline 39 & Hybrid lesion & Prenatal diagnosis & 3 months & $\begin{array}{l}\text { Small air-filled cysts, } \\
\text { systemic artery }\end{array}$ & LLL & Pathology & Lobectomy \\
\hline 4 & Cystic CPAM type 1 & Prenatal diagnosis & 3 months & Large air-filled cysts & LUL & Pathology & Lobectomy \\
\hline 5 & Cystic CPAM type 1 & Incidental finding & 12 years & Large air-filled cysts & LLL & Pathology, CT & Lobectomy \\
\hline 14 & Cystic CPAM type 1 & Prenatal diagnosis & 4 months & Large air-filled cysts & RLL & Pathology & Lobectomy \\
\hline
\end{tabular}


Table 3 (continued)

\begin{tabular}{|c|c|c|c|c|c|c|c|}
\hline Case \# & Final diagnosis & Presentation & Patient age & MRI findings & Location & Proof of diagnosis & Management \\
\hline 23 & Cystic CPAM type 1 & Prenatal diagnosis & 4 months & Large air-filled cysts & LUL & Pathology, CT & Lobectomy \\
\hline 35 & Cystic CPAM type 1 & Incidental finding & 15 months & Large air-filled cyst & LLL & Pathology & Lobectomy \\
\hline 9 & Cystic CPAM type 2 & Prenatal diagnosis & 8 months & Small air-filled cysts & RUL & Pathology, CT & Lobectomy \\
\hline 16 & Cystic CPAM type 2 & Prenatal diagnosis & 2 months & $\begin{array}{l}\text { Small air-filled cysts, } \\
\text { systemic artery* }\end{array}$ & RLL & Pathology & Lobectomy \\
\hline 19 & Cystic CPAM type 2 & Prenatal diagnosis & 4 months & Small air-filled cysts & ML & Pathology, CT & Lobectomy \\
\hline 21 & Cystic CPAM type 2 & Prenatal diagnosis & 3 months & Small air-filled cysts & RUL & Pathology & Lobectomy \\
\hline 20 & MAPCAs & Prenatal diagnosis & 3 days & $\begin{array}{l}\text { Systemic arteries (direct } \\
\text { MAPCAs) }\end{array}$ & RUL, LLL & Surgery & Total repair** \\
\hline 2 & Scimitar syndrome & Incidental finding & 30 months & $\begin{array}{l}\text { Hypoplastic right lung, } \\
\text { PAPVR, systemic } \\
\text { artery }\end{array}$ & Right lung & $\begin{array}{l}\text { Surgery, } \\
\quad \text { angiography, CT }\end{array}$ & PAPVR repair \\
\hline 18 & Scimitar syndrome & $\begin{array}{l}\text { Recurrent airway } \\
\text { infection }\end{array}$ & 25 months & $\begin{array}{l}\text { Hypoplastic right lung, } \\
\text { PAPVR, systemic } \\
\text { artery }\end{array}$ & Right lung & Echocardiography & Conservative \\
\hline 28 & Scimitar syndrome & Incidental finding & 2 months & $\begin{array}{l}\text { Hypoplastic right lung, } \\
\text { PAPVR, systemic } \\
\text { artery }\end{array}$ & Right lung & Echocardiography & Conservative \\
\hline 22 & Scimitar syndrome & Respiratory distress & 6 days & $\begin{array}{l}\text { Hypoplastic right lung, } \\
\text { PAPVR, systemic } \\
\text { arteries }\end{array}$ & Right lung & $\begin{array}{l}\text { Surgery, } \\
\quad \text { angiography, CT }\end{array}$ & $\begin{array}{l}\text { PDA closure, } \\
\text { PAPVR } \\
\text { repair }\end{array}$ \\
\hline 34 & Pulmonary AVM & Hypoxemia & 6 days & $\begin{array}{l}\text { Enhancing mass lesion } \\
\text { with pulmonary } \\
\text { arterial and venous } \\
\text { connection }\end{array}$ & RLL & Angiography & Embolisation \\
\hline
\end{tabular}

$A V M$ arteriovenous malformation, $C P A M$ congenital pulmonary airway malformation, $C X R$ chest radiograph, $L L L$ left lower lobe, $L U L$ left upper lobe, $M A P C A$ major aortopulmonary collateral artery, $M L$ middle lobe, $P A P V R$ partial anomalous pulmonary venous return, $P D A$ patent ductus arteriosus, $R U L$ right upper lobe, $R L L$ right lower lobe

* Phrenic artery misinterpreted as systemic arterial supply to lung

** Pulmonary atresia repair with right ventricle to pulmonary artery conduit and unifocalisation of pulmonary arteries

All bronchopulmonary lesions presented as perfusion defect at peak lung enhancement (Figs. 3, 4 and 5). All isolated overinflation showed decreased peak enhancement, with a pulmonary arterial peak in 5/17 (29.4\%) lesions and a delayed peak in 12/17 (70.6\%). Sequestrations showed delayed and increased (4/7, $57.1 \%)$, similar $(1 / 7,14.3 \%)$ or decreased $(2 / 7,28.6 \%)$ peak enhancement compared to normal lung parenchyma. Lung lesions with detectable systemic arteries showed significantly higher enhancement ratios than those without a detectable systemic artery (mean \pm SD: $0.97 \pm 0.62$ vs. $0.40 \pm 0.23, P=0.009$, independent samples $t$-test) but no significant difference in the delay of peak enhancement (mean \pm SD: $2.9 \pm 1.2 \mathrm{~s}$ vs. $2.1 \pm 2.0 \mathrm{~s}$, $P=0.237$, independent samples $t$-test). Median and interquartile range for the delay of peak enhancement was $2.8 \mathrm{~s}(0.5$ to $4.0 \mathrm{~s})$ for all non-cystic pulmonary lesions. Perfusion parameters for the different lung lesions are detailed in Table 4.

Table 4 Perfusion parameters of 31 congenital lung lesions and corresponding normal lung parenchyma

\begin{tabular}{|c|c|c|c|c|c|}
\hline \multirow[t]{2}{*}{ Entity } & \multirow[b]{2}{*}{$n$} & \multicolumn{2}{|c|}{$\begin{array}{l}\text { Signal enhancement integral (arbitrary } \\
\text { units, mean } \pm \text { SD) }\end{array}$} & \multirow{2}{*}{$\begin{array}{l}\text { Enhancement ratio } \\
\text { (median }[\mathrm{IQR}] \\
\text { or mean } \pm \mathrm{SD} \text { ) }\end{array}$} & \multirow{2}{*}{$\begin{array}{l}\text { Delay of peak } \\
\text { enhancement } \\
(\mathrm{s}, \text { median }[\mathrm{IQR}] \\
\text { or mean } \pm \mathrm{SD})\end{array}$} \\
\hline & & Normal lung & Lesion & & \\
\hline Isolated overinflation & 17 & $417 \pm 204$ & $144 \pm 85^{*}$ & $0.4(0.2-0.5)$ & $2.1(0.0-4.1)$ \\
\hline Bronchopulmonary sequestration & 7 & $385 \pm 297$ & $415 \pm 306$ & $1.3 \pm 0.6$ & $3.1 \pm 0.7$ \\
\hline Hybrid lesion & 3 & $689 \pm 313$ & $287 \pm 196$ & $0.4 \pm 0.1$ & $2.0,2.2,4.5$ \\
\hline $\begin{array}{l}\text { Lung area with systemic supply } \\
\text { in scimitar syndrome }\end{array}$ & 4 & $560 \pm 259$ & $322 \pm 212$ & $0.6 \pm 0.2$ & $0.0,3.4,3.8,3.9$ \\
\hline
\end{tabular}

$S D$ standard deviation, IQR interquartile range

* Comparison between lesion and normal lung with paired $t$-test, $P=0.0001$ 


\section{Comparison between MRI and CT}

A comparison of the MRI studies to CT examinations was available in 13/39 (33.3\%) patients. In 7/13 (53.8\%) patients, earlier CT studies had been performed $(5 / 7,71.4 \%$ at referring hospitals) and MRI was obtained as follow-up for surgical planning at our institution. In 6/13 (46.2\%) patients, CT was performed after MRI: as preoperative follow-up for surgical planning in 4/6 (66.7\%) cases and for assessing airway compression in 2 cases. On average, CT was performed 23 days (median) before MRI, ranging from 2 years before to 6 months after MRI.

In these 13 patients, the MRI and CT diagnosis and classification of 16 detected abnormalities were concordant in all cases. All $(6 / 6,100 \%)$ systemic arteries were detected both on $\mathrm{CT}$ and MRI. In 14 lung lesions, the volume of the lesions measured slightly smaller on MRI than on CT (mean difference- $0.4 \mathrm{ml}$, limits of agreement $-1.6 \mathrm{ml}$ to $0.9 \mathrm{ml}$ ).

\section{Discussion}

In the surgical, pathological and imaging literature, numerous terminologies are used to describe congenital pulmonary lesions. For this study, we formulated an imaging classification (Table 2) that takes into account the heterogeneous nature and characteristics of the diverse congenital malformations. Our classification was based on and modified from previous descriptions of pathological features by Stocker [22], Langston [1] and an imaging review by Newman [2].

With this retrospective study, we show that dedicated lung MRI can detect, localise and classify congenital bronchopulmonary foregut anomalies with high accuracy and very good agreement between readers. In the 39 patients, 44/46 (95.6\%) abnormalities were correctly classified compared to an expert diagnosis based on pathology, surgery and/or other imaging. Only 2/39 (5.1\%) lung lesions were misclassified due to misinterpretation of imaging findings: one case of bronchial atresia as cystic pulmonary malformation and one isolated overinflation as hybrid lesion. In the subgroup of our patients who underwent MRI and CT (13/ $39,33.3 \%$ ), the concordance rates between MRI and CT were $100 \%$ for both lesion classification and detection of systemic arteries. In the subgroup of our patients with resected lung lesions (24 patients, 28 lung lesions), the concordance rate between MRI and pathology was $92.9 \%$ for diagnosing and detecting systemic arteries. Overall, the agreement between MRI and the final diagnosis in our study was comparable to that reported for contrast-enhanced CT and pathology in recent series. Mon et al. [23] described concordance rates between $\mathrm{CT}$ and pathology for diagnosing congenital pulmonary airway malformation of $83.5 \%$ and detecting systemic feeding arteries of $90.2 \%$. Narayan et al. [24] reported similar diagnoses at CT and pathology in 40/45 children with resected congenital lung lesions (concordance rate: $88.9 \%$ ).

On MRI, respiratory gated T2-weighted fast spin echo sequences with radial readout allowed the differentiation between consolidation, cystic lesions filled with air or fluid, and hyperinflated lung parenchyma filled with fluid in the first days of life or with air later on. Bronchial remnants impacted with mucus were detected as linear, branching or more globular structures with high signal intensity in different types of isolated overinflation (bronchial atresia, segmental overinflation) but also in bronchopulmonary sequestrations and hybrid lesions. The presence of mucoid impaction may confirm the hypothesis that these lung lesions are related to airway obstruction with secondary pulmonary dysplastic changes and associated vascular anomalies [25].

The dynamic contrast-enhanced series helped detect bronchopulmonary lung lesions as they all presented as a perfusion defect during peak pulmonary enhancement. In addition, the dynamic series allowed the differentiation between atelectasis with increased signal intensity and consolidation as part of the lung lesion with perfusion defect at peak pulmonary enhancement. Systemic arterial supply and abnormal pulmonary venous drainage of the lung lesions could be detected on angiographic images from the dynamic contrastenhanced series, while the evaluation of parenchymal perfusion allowed the further description of the vascular supply of pulmonary abnormalities. Lung areas of overinflation, bronchopulmonary sequestrations, hybrid lesions and normal lung parts supplied by systemic arteries showed delayed peak enhancement of about 2 to $4 \mathrm{~s}$, which indicates predominantly systemic arterial supply of these lesions due to either absent pulmonary arteries or decreased pulmonary arterial perfusion as a sequelae of hypoventilation and decreased oxygen saturation. While contrast-enhanced CT may delineate small vessels comparable to MRI, the perfusion information obtained with a dynamic MRI series is novel in the investigation of congenital lung lesions.

With the clinical introduction of ultrashort echo time sequences for lung MRI, there is hope that these sequences may better delineate small cystic lesions than current techniques do. However, in our preliminary experience with four congenital lung lesions, areas of overinflation are not very conspicuous and consolidation may obscure systemic feeding arteries.

The main limitation of our study is its retrospective nature, which could have introduced a selection bias. However, we believe this selection bias to be relatively small as almost all patients with congenital lung malformations seen at our institution during the study period underwent MRI. Other limitations include the lack of surgery and pathology for confirmatory diagnosis in one-third of our patient cohort, since not all patients received surgery for their abnormality. Therefore, final expert diagnosis was based only on other imaging for these patients. This reflects the current praxis that some 
congenital bronchopulmonary abnormalities are not treated by surgery but managed conservatively [11, 17, 21, 26, 27]. At our centre, we follow prenatally detected lung lesions by foetal US and consider foetal MRI for prognostic purposes. After birth, we acquire lung MRI for confirmation of the lesion and for planning treatment. In asymptomatic infants, the postnatal MRI examination is usually obtained between 3 and 5 months of age, so it can be performed without general anaesthesia and used to assess the need for surgical treatment, which is usually scheduled around the age of 6 months. Large bronchopulmonary sequestrations with relevant shunt and congenital pulmonary airway malformations are generally resected due to the risk of infection [2]. We also recommend resection of multicystic lung lesions (CPAM types 1 and 2), because they cannot reliably be differentiated from cystic bronchopulmonary blastoma on gross pathology or imaging $[2,28]$. Conservative management is considered for asymptomatic lesions with overinflation.

The main drawback of dedicated lung MRI is the rather long imaging time that requires sedation in small children. Although fast lung imaging is possible with single-shot fast spin echo or steady-state free precession techniques, in our experience these fast sequences alone are not sufficient for characterising parenchymal lung lesions and they do not provide sufficient information on lung vasculature or perfusion [29]. By limiting the MRI protocol to respiratory-gated fast spin echo sequences in two planes and the dynamic contrastenhanced series, the imaging time could be reduced to approximately $10 \mathrm{~min}$. Currently, we consider gadoliniumbased contrast agents indispensable for MRI assessment of most congenital thoracic malformations, mainly for delineation of pathological vessels and reliable detection of lung lesions. Like many other paediatric centres, we have stopped using linear gadolinium compounds and only apply macrocyclic agents, for which deposition in tissue appears to be less or absent [30].

The choice of the imaging modality for postnatal assessment of congenital thoracic malformations will depend on the image quality achievable by the MRI and CT equipment available. If a fast multi-row detector CT scanner allowing artefact free imaging of lung parenchyma in free-breathing infants is available, one will have to weigh the risk of ionising radiation from CT against the risk of sedation and gadolinium deposition in tissues for MRI [31].

\section{Conclusion}

Dedicated lung MRI can reliably delineate parenchymal and vascular components of lung lesions in young children. Dynamic contrast-enhanced sequences facilitate their detection and provide information on lung perfusion. Therefore, comprehensive imaging characterisation of congenital bronchopulmonary malformations has become feasible and dedicated lung MRI may be considered a radiation-free alternative to contrast-enhanced $\mathrm{CT}$.

\section{Compliance with ethical standards}

\section{Conflicts of interest None}

Open Access This article is licensed under a Creative Commons Attribution 4.0 International License, which permits use, sharing, adaptation, distribution and reproduction in any medium or format, as long as you give appropriate credit to the original author(s) and the source, provide a link to the Creative Commons licence, and indicate if changes were made. The images or other third party material in this article are included in the article's Creative Commons licence, unless indicated otherwise in a credit line to the material. If material is not included in the article's Creative Commons licence and your intended use is not permitted by statutory regulation or exceeds the permitted use, you will need to obtain permission directly from the copyright holder. To view a copy of this licence, visit http://creativecommons.org/licenses/by/4.0/.

\section{References}

1. Langston C (2003) New concepts in the pathology of congenital lung malformations. Semin Pediatr Surg 12:17-37

2. Newman B (2006) Congenital bronchopulmonary foregut malformations: concepts and controversies. Pediatr Radiol 36: 773-791

3. Burge D, Wheeler R (2010) Increasing incidence of detection of congenital lung lesions. Pediatr Pulmonol 45:103 author reply 104

4. Bush A (2001) Congenital lung disease: a plea for clear thinking and clear nomenclature. Pediatr Pulmonol 32:328-337

5. Barth RA (2012) Imaging of fetal chest masses. Pediatr Radiol 42(Suppl 1):S62-S73

6. Peters RT, Burge DM, Marven SS (2013) Congenital lung malformations: an ongoing controversy. Ann R Coll Surg Engl 95:144-147

7. Azizkhan RG, Crombleholme TM (2008) Congenital cystic lung disease: contemporary antenatal and postnatal management. Pediatr Surg Int 24:643-657

8. Hubbard AM, Adzick NS, Crombleholme TM et al (1999) Congenital chest lesions: diagnosis and characterization with prenatal MR imaging. Radiology 212:43-48

9. Recio Rodriguez M, Martinez de Vega V, Cano Alonso R et al (2012) MR imaging of thoracic abnormalities in the fetus. Radiographics 32:E305-E321

10. Alamo L, Reinberg O, Vial Y et al (2013) Comparison of foetal US and MRI in the characterisation of congenital lung anomalies. Eur J Radiol 82:e860-e866

11. Liszewski MC, Ciet P, Lee EY (2019) MR imaging of lungs and Airways in Children: past and present. Magn Reson Imaging Clin N Am 27:201-225

12. Epelman M, Kreiger PA, Servaes $S$ et al (2010) Current imaging of prenatally diagnosed congenital lung lesions. Semin Ultrasound CT MR 31:141-157

13. Pumberger W, Hormann M, Deutinger J et al (2003) Longitudinal observation of antenatally detected congenital lung malformations (CLM): natural history, clinical outcome and long-term follow-up. Eur J Cardiothorac Surg 24:703-711

14. Downard CD, Calkins CM, Williams RF et al (2017) Treatment of congenital pulmonary airway malformations: a systematic review 
from the APSA outcomes and evidence based practice committee. Pediatr Surg Int 33:939-953

15. Hardee S, Tuzovic L, Silva CT et al (2017) Congenital cystic lung lesions: evolution from in-utero detection to pathology diagnosis-a multidisciplinary approach. Pediatr Dev Pathol 20:403-410

16. Haggerty JE, Smith EA, Kunisaki SM, Dillman JR (2015) CT imaging of congenital lung lesions: effect of iterative reconstruction on diagnostic performance and radiation dose. Pediatr Radiol 45:989997

17. Ng C, Stanwell J, Burge DM, Stanton MP (2014) Conservative management of antenatally diagnosed cystic lung malformations. Arch Dis Child 99:432-437

18. Paramalingam S, Parkinson E, Sellars M et al (2010) Congenital segmental emphysema: an evolving lesion. Eur J Pediatr Surg 20: 78-81

19. Chowdhury MM, Chakraborty S (2015) Imaging of congenital lung malformations. Semin Pediatr Surg 24:168-175

20. Thacker PG, Schooler GR, Caplan MJ, Lee EY (2015) Developmental lung malformations in children: recent advances in imaging techniques, classification system, and imaging findings. J Thorac Imaging 30:29-43

21. Amaxopoulou C, Gnannt R, Higashigaito K et al (2018) Structural and perfusion magnetic resonance imaging of the lung in cystic fibrosis. Pediatr Radiol 48:165-175

22. Stocker J (2002) Congenital pulmonary airway malformation - a new name for and an expanded calssification of congenital cystic adenomatoid malformation of the lung, symposium 24: nonneoplastic lung disease. Histopathology 41:424-431

23. Mon RA, Johnson KN, Ladino-Torres M et al (2019) Diagnostic accuracy of imaging studies in congenital lung malformations. Arch Dis Child Fetal Neonatal Ed 104:F372-F377

24. Narayan RR, Abadilla N, Greenberg DR et al (2019) Predicting pathology from imaging in children undergoing resection of congenital lung lesions. J Surg Res 236:68-73
25. Biyyam DR, Chapman T, Ferguson MR et al (2010) Congenital lung abnormalities: embryologic features, prenatal diagnosis, and postnatal radiologic-pathologic correlation. Radiographics 30: $1721-1738$

26. Sauvat F, Michel JL, Benachi A et al (2003) Management of asymptomatic neonatal cystic adenomatoid malformations. J Pediatr Surg 38:548-552

27. Cook J, Chitty LS, De Coppi P et al (2017) The natural history of prenatally diagnosed congenital cystic lung lesions: long-term follow-up of 119 cases. Arch Dis Child 102:798-803

28. Messinger YH, Stewart DR, Priest JR et al (2015) Pleuropulmonary blastoma: a report on 350 central pathology-confirmed pleuropulmonary blastoma cases by the International Pleuropulmonary Blastoma Registry. Cancer 121:276-285

29. Gnannt R, Amaxopoulou CE, Goetti R et al (2014) Qualitative assessment of MRI sequences for morphological imaging of the lungs in children with cystic fibrosis. Pediatr Radiol 44(Suppl 2): S308

30. Blumfield E, Swenson DW, Iyer RS, Stanescu AL (2019) Gadolinium-based contrast agents - review of recent literature on magnetic resonance imaging signal intensity changes and tissue deposits, with emphasis on pediatric patients. Pediatr Radiol 49: 448-457

31. Callahan MJ, MacDougall RD, Bixby SD et al (2018) Ionizing radiation from computed tomography versus anesthesia for magnetic resonance imaging in infants and children: patient safety considerations. Pediatr Radiol 48:21-30

Publisher's note Springer Nature remains neutral with regard to jurisdictional claims in published maps and institutional affiliations. 